collaboration with the nursing staff taking into consideration the difficulties they may encounter.

Conclusion and relevance This training made it possible to raise awareness of the proper use of the anti-return valves to secure them in a secure way. It has helped to foster collaboration between pharmacy preparers and the nursing staff, the nurse bringing his technical knowledge of the care and the pharmacy preparer on the equipment. A post-training audit will be organized within a few months in the cardiology intensive care unit.

On the strength of this success, we wish to continue the development of trainings dispensed by a pharmacy technician and a nurse of another care service.

\section{NP-007 A MIXED METHODS EVALUATION OF THE CROSS- SECTOR PHARMACIST VOCATIONAL TRAINING FOUNDATION PROGRAMME: IS THE TRAINING PROGRAMME FIT FOR PURPOSE?}

${ }^{1} \mathrm{FJ}$ McMillan, ${ }^{1} \mathrm{~A}$ Power, ${ }^{2} \mathrm{C}$ Bond, ${ }^{2} \mathrm{~J}$ Clelland, ${ }^{2} \mathrm{~J}$ Inch. ${ }^{1}$ Pharmacy, NHS Education for UK; ${ }^{2}$ Aberdeen University

\subsection{6/ejhpharm-2020-eahpconf.465}

Background and importance Pharmacists increasingly have portfolio careers, in different settings, including hospital, community and primary care.

Aim and objectives A cross-sector Pharmacist Foundation Training programme was introduced in Scotland from September $2017^{1}$ to develop transferable skills and competences for pharmacists working in these sectors. The aim was to assess the effectiveness of the programme.

Materials and methods The approach was underpinned by two theoretical frameworks. ${ }^{2} 3$ Pharmacists and tutors were invited to take part in focus groups at baseline, mid, and end-of-training, to explore their experiences. Proceedings were audiorecorded and transcribed. On-line baseline and end-of-training self-assessment questionnaires and routine assessment data were analysed.

Data was managed in nVIVO v11 and analysed thematically Quantitative data from the questionnaires and assessments was analysed in SPSS and Excel.

Results Of the 72 registered FPs, 48 (67\%) completed a baseline questionnaire. Twenty pharmacists (28\%) and 16 tutors attended a focus group. Preliminary focus group themes include training/support needs, professional identity, patient safety, and training barriers/facilitators. Tutors highlighted skill gaps and noted variation in competence, training and support needs.

Questionnaire analyses suggest that pharmacists feel part of the team. They are confident communicating with patients/ carers, meeting their needs, and managing pharmaceutical care issues. but have less confidence dealing with supply chain issues or applying local formularies.

Conclusions and relevance Baseline data suggests pharmacists' high self-assessed competence is not matched by reflective focus group discussions or tutor feedback. Ongoing evaluation will confirm if the programme has enabled the development of the requisite competences for future practice.

\section{REFERENCES AND/OR ACKNOWLEDGEMENTS}

1. The Pharmacist Vocational Training programme. https://www.nes.scot.nhs.uk/edu cation-and-training/by-discipline/pharmacy/pharmacists/pharmacy-vocational-training.aspxAccessed August 2018

2. Miller GE. The assessment of clinical skills/competence/performance. Academic Medicine 1990:65(9). September Supplement.

3. Lave J, Wenger E. Situated learning: legitimate peripheral participation. Cambridge: Cambridge University Press; 1991.

\section{NP-008 MONITORING OF PRESCRIPTIONS ON PROPHYLAXIS OF VENOUS THROMBOEMBOLISM (VTE) IN MEDICAL PATIENTS IN BEATRIZ ÂNGELO HOSPITAL}

F Tátá*, P Cardoso, L Soares, R Figueiredo, T Lobo, M Capoulas, A Loba, E Marques, C Santos. Hospital Beatriz Ângelo, Loures, Portugal

\subsection{6/ejhpharm-2020-eahpconf.466}

Background and importance VTE is an important public health problem because of its impact in terms of morbidity, mortality, and associated costs. VTE prevention is a priority strategy to improve patient safety. More than half of all hospitalised patients are at risk for VTE. Previous studies have reported overall VTE prophylaxis rates ranging from $13 \%$ to $64 \%$.

Aim and objective To assess the risk of VTE in patients hospitalised for medical pathology, using clinical records using the Padua score. Classify patients according to prescription, risk factors (RF) and contraindication (CI). To verify the use of a VTE risk assessment model. Create a computer application with the Padua score and integrate it into the prescription program.

Materials and methods Descriptive observational study during September in the medical patients admitted with age $\geq 18$ years. Patients were classified according to the Padua score, LMWH prescription and contraindications in 5 populations: (a) with prescription and without RF or CI, (b) without prescription and with RF (c) with an unadjusted dose (d) with prescription and with RF, (e) without prescription and without $\mathrm{RF}$ or CI. Pharmaceutical intervention was performed in patients classified in (a), (b) and (c), pharmaceutical intervention, medical justification and information on the use of a VTE evaluation model were recorded.

Results Of the total number of patients (218), 66.5\% had a risk of VTE of these $58.7 \%$ had no CI for pharmacological prophylaxis. Of the $58.7 \%, 42 \%$ do not have prescription of prophylaxis or have dose misfit. Of the population without risk of VTE $35.6 \%$ have a prescription of prophylaxis. Of the population at risk of VTE and cancer, 39\% do not have prophylaxis whereas in the population at risk of VTE and without cancer, $18 \%$ have no prescription. A pharmaceutical intervention was performed in $81 \%$ of the prescriptions with an acceptance rate of $29 \%$.

Conclusion and relevance According to the results, $42 \%$ of the patients do not have prophylactic prescription or have an unadjusted dose. In patients with score $\geq 4$ and without CI, the prophylaxis percentage is lower in cancer patients. The vast majority of physicians still do not use a VTE risk assessment model. The application with Padua score was presented to physicians. 